\title{
PERBEDAAN MOTIVASI BERPARTISIPASI DALAM OLAHRAGA ANTARA SUKU OSING DAN SUKU JAWA
}

\author{
Sujari ${ }^{1}$, Abd. Shomad ${ }^{2}$, Danang Ari Santoso ${ }^{1}$ \\ ${ }^{1}$ Pendidikan Jasmani Kesehatan dan Rekreasi, Universitas PGRI Banyuwangi \\ ${ }^{2}$ Pendidikan Sejarah, Universitas PGRI Banyuwangi
}

\begin{abstract}
Sports aspect is so closely associated with psychology. It thought by sports activities is specialy the goal. Sports can be a target at achieving review of its achievements as competitive, also keep a target to review the healthty, fitness and stamina Body. The role of motivation to participate that so important to review knowing up where is somebody engaged hearts routine sport activities. An athlete is individual thing has uniqueness, above all different etnic group. An athlete has a talent, has a habits and has a culture and different background that influence affects on himself. Various differences that sport participant motivation not would be the same. This operates is quantitative research is non-experimental (ex post facto) with collection approach.Independent research is etnic group. The research of the samples is a student of osing and Javanese etnic group using cluster sampling amounted to 30 peoples. Based from studies showing the dominant etnic group of osing have a more skill factor development, status, energy release, a team atmosphere, and affiliates be comperated then java etnic group. Can be conclouded if different racist make influance can be affecting of motivation to participate in sport and progressive achievement improvement etnic group of osing.
\end{abstract}

Keywords: participant motivation, osing, javanese etnic

\begin{abstract}
ABSTRAK
Olahraga sangat erat kaitannya dengan aspek psikologi. Hal ini berdasarkan pemikiran bahwa kegiatan berolahraga merupakan suatu tingkah laku yang khas dan bertujuan. Olahraga dapat bertujuan untuk mencapai suatu prestasi karena sifatnya yang kompetitif, dapat juga bertujuan untuk menjaga kesehatan, kebugaran, dan stamina tubuh. Peran motivasi berpartisipasi sangatlah penting untuk mengetahui sampai dimana seseorang terlibat dalam rutinitas kegiatan olahraga. Seorang atlet adalah individu yang memiliki keunikan tersendiri, apalagi dalam sebuah suku yang berbeda. Ia memiliki bakat tersendiri, kebiasaan tersendiri dan budaya tersendiri serta latar belakang yang mempengaruhi secara spesifik pada dirinya. Beragam perbedaan itulah yang menyebabkan motivasi berpartisipasi dalam olahraga juga tidak akan sama. Jenis penelitian ini adalah penelitian kuantitatif noneksperimen (ex post facto) dengan pendekatan survei. Variabel bebas dalam penelitian ini adalah suku. Sampel dalam penelitian ini adalah mahasiswa suku Osing dan suku Jawa dengan menggunakan teknik cluster sampling yang berjumlah 30 orang. Berdasarkan dari hasil penelitian menunjukkan bahwa suku osing lebih dominan pada faktor skill development, status, energy release, team atmosphere, dan affiliation dibandingkan dengan suku jawa. Sedangkan pada faktor fitness suku jawa lebih dominan daripada suku osing. Sehingga dapat disimpulkan bahwa perbedaan suku dapat mempengaruhi motivasi berpartisipasi dalam olahraga dan Suku Osing lebih progressive dalam peningkatan prestasi.
\end{abstract}

Kata kunci: motivasi berpartisipasi, suku osing, suku jawa 
PENDAHULUAN

Olahraga sangat erat kaitannya

dengan aspek psikologi. Hal ini berdasar-

kan pemikiran bahwa kegiatan berolahraga merupakan suatu tingkah laku yang

khas dan bertujuan. Olahraga dapat bertujuan untuk mencapai suatu prestasi karena sifatnya yang kompetitif, dapat juga bertujuan untuk menjaga kesehatan, kebugaran, dan stamina tubuh. Peran motivasi berpartisipasi sangatlah penting untuk mengetahui tingkat keterlibatan seseorang dalam rutinitas kegiatan olahraga.

Seorang atlet adalah individu yang memiliki keunikan tersendiri, apalagi dalam sebuah suku yang berbeda. Ia memiliki bakat tersendiri, kebiasaan tersendiri dan budaya tersendiri serta latar belakang yang mempengaruhi secara spesifik pada dirinya. Beragam perbedaan itulah motivasi berpartisipasi dalam olahraga juga tidak akan sama. Karena setiap individu mempunyai persepsi dan keinginan yang berbeda sesuai dengan apa yang mereka pikirkan. Menurut Gould dan Petlickoff (dalam
Maksum, 2011) bahwa motivasi seseorang berpartisipasi dalam olahraga beragam mulai dari (1) ingin mendapatkan sebuah kesenangan demi kepuasan tersendiri, (2) mendapatkan kepercayaan diri, (3) mendapatkan hubungan sosial dengan teman baru, (4) memperoleh hal-hal baru sebagai pengalaman, (5) mendapatkan sebuah kesuksesan, dan (6) yang tidak kalah pentingnya adalah kondisi fisik yang bugar. Orang tua merupakan motivator yang paling utama dalam sebuah keluarga untuk secara langsung mengajak anggota keluarga berprestasi setinggi-tingginya (Maksum, 2009). Motivasi berpartisipasi dalam olahraga sangatlah beragam setiap individunya, ini dikarenakan sebuah kepentingan pribadi untuk mendapatkan sebuah kepuasan dan pembudayaan dalam sebuah keluarga atau adat suku yang berbeda sehingga tingkatan motivasinya akan berbeda pula.

Motivasi berpartisipasi dalam budaya akan berbeda antara budaya yang satu dengan yang lainnya. Setiap budaya 
mempunyai aturan atau norma yang mengatur sosial budayanya sehingga menciptakan lingkungan dan paradigma individu yang berbeda. Ini menyebabkan setiap individu mempunyai ciri khas sesuai dengan budaya mereka.

Berdasarkan penelitian Park (2006) tentang motivasi untuk berpartisipasi dalam olahraga ketangkasan antara mahasiswa Amerika dan mahasiswa Korea. Mahasiswa Amerika lebih tinggi dibandingkan dengan mahasiwa Korea, termasuk dalam hal orientasi terhadap prestasi, orientasi terhadap tim, kebugaran, penyaluran energi, bermacam alasan lain yang tidak diperinci, pengembangan keterampilan, persahabatan, dan orientasi terhadap kesenangan, terlepas dari perbedaan gender, tingkat pendidikan, tingkat keterampilan, dan jumlah rata-rata hari yang digunakan untuk berpartisipasi dalam olahraga ketangkasan.

Indonesia yang mempunyai banyak keragaman budaya menyebabkan perbedaan karakter dan pengambilan keputusan dalam segala hal. Perbedaan ini membuat motivasi berpartisipasi dalam olahraga juga akan berbeda. Sehingga banyak cabang olahraga yang diminati oleh suku tertentu.

\section{Motivasi Berpartisipasi}

Motivasi adalah sebuah dorongan yang ada pada diri seseorang untuk melakukan sebuah aktivitas. Motivasi didefinisikan sebagai penggerak atau dorongan seseorang untuk melakukan sesuatu yang memiliki arah dan intensitas (Maksum, 2011). Sedangkan menurut Darmawan (2008) motivasi didefinisikan sebagai suatu kecenderungan diri seseorang untuk melakukan aktivitas, mulai dari dorongan dari dalam diri (drive) dan diakhiri dengan sebuah penyesuaian diri. Sehingga dapat disimpulkan bahwa motivasi merupakan aktualisasi dari sumber penggerak tersebut untuk melakukan sebuah aktivitas.

Kootz et al. (Darmawan, 2008) mendefinisikan motivasi sebagai suatu reaksi yang diawali dengan adanya kebutuhan yang menimbulkan keinginan atau 
upaya mencapai tujuan, selanjutnya menimbulkan ketegangan, kemudian menyebabkan timbulnya tindakan yang mengarah pada tujuan dan akhirnya dapat memuaskan. Sedangkan menurut Darmawan (2008) motivasi merupakan suatu penggerak atau dorongan yang terdapat dalam diri manusia, yang dapat menimbulkan, mengarahkan dan mengorganisasikan tingkah lakunya. Dari beberapa pendapat di atas, maka dapat disimpulkan motivasi merupakan dorongan yang timbul dari dalam diri individu atas dasar adanya kebutuhan yang menggerakkan individu untuk melakukan tindakan agar tujuannya tercapai.

\section{Suku Osing}

Dalam bahasa Osing kata "Osing" itu sendiri berarti "tidak", dan kata "Osing" ini mewakili keberadaan orang Osing yang ada di Banyuwangi. Suku Osing biasa disebut Wong Osing, Lare Osing, dan Tiyang Osing yang berarti saya orang Osing (Anastasia, 2013).
Secara geografis, suku Osing

mendiami daerah dalam Kabupaten Banyuwangi. Walaupun kehadiran sukusuku lain yang ada di Banyuwangi seperti Jawa, Madura, dan Bugis, tidak merubah pandangan umum bahwa yang disebut sebagai masyarakat Banyuwangi ialah masyarakat Osing. Masyarakat Osing tersebar di beberapa kecamatan seperti Glagah, Giri, Kabat, Rogojampi, Singojuruh, Cluring, dan Genteng.

Dari berbagai kecamatan tersebut, kecamatan yang penduduknya masih kental menganut adat istiadat dan budaya khas sebagai satu suku ialah desa Kemiren di kecamatan Glagah. Desa Kemiren telah dikenal sebagai desa adat suku Osing yang menjadi tujuan utama wisata di Banyuwangi.

\section{Suku Jawa}

Indonesia merupakan Negara kepulauan, Jawa merupakan salah satu pulau dari kepulauan yang ada di Indonesia. Pada hakikatnya masyarakat di Pulau Jawa adalah orang-orang yang berasal dari suku 
Jawa, tetapi seiring dengan perkembangan jaman banyak orang-orang dari suku lain yang datang ke pulau Jawa. Jadi secara antropologi budaya dapat dikatakan bahwa yang disebut suku Jawa adalah orangorang yang secara turun-temurun menggunakan bahasa Jawa dan bertempat tinggal di daerah Jawa (Herusatoto, 2005).

Suku Jawa adalah suku terbesar di Indonesia. Mereka berasal dari pulau Jawa dan terutama ditemukan di Provinsi Jawa Tengah dan Jawa Timur, tetapi di Provinsi Jawa Barat juga ditemukan yaitu di Kabupaten Indramayu dan Cirebon yang mayoritas masyarakatnya merupakan orangorang Jawa yang berbahasa dan berbudaya Jawa.

Karakteristik budaya Jawa adalah religius, non-doktriner, toleran, akomodatif, dan optimistik. Karakteristik seperti ini melahirkan corak, sifat, dan kecenderungan yang khas bagi masyarakat Jawa seperti berikut: 1) percaya kepada Tuhan Yang Maha Esa sebagai Sangkan Paraning Dumadi, dengan segala sifat dan kebesaran-
Nya; 2) bercorak idealistis, percaya kepada sesuatu yang bersifat immateriil (bukan kebendaan) dan hal-hal yang bersifat adikodrati (supernatural) serta cenderung ke arah mistik; 3) lebih mengutamakan hakikat daripada segi-segi formal dan ritual; 4) mengutakaman cinta kasih sebagai landasan pokok hubungan antar manusia; 5) percaya kepada takdir dan cenderung bersikap pasrah; 6) bersifat konvergen dan universal; 7) momot dan nonsektarian; 8) cenderung pada simbolisme; 9) cenderung pada gotong royong, guyub, rukun, dan damai; dan 10) kurang kompetitif dan kurang mengutamakan materi (Suyanto, dalam Marzuki, 2006).

Pandangan hidup Jawa memang berakar jauh ke masa lalu. Masyarakat Jawa sudah mengenal Tuhan sebelum datangnya agama-agama yang berkembang sekarang ini. Semua agama dan kepercayaan yang datang diterima dengan baik oleh masyarakat Jawa. Mereka tidak terbiasa mempertentangkan agama dan keyakinan. Mereka menganggap bahwa semua 
agama itu baik dengan ungkapan mereka:

"sedaya agami niku sae" (semua agama itu baik). Ungkapan inilah yang kemudian membawa konsekuensi timbulnya sinkretisme di kalangan masyarakat Jawa.

Masyarakat Jawa yang menganut Islam sinkretis hingga sekarang masih banyak ditemukan, terutama di Yogyakarta dan Surakarta. Mereka akan tetap mengakui Islam sebagai agamanya, apabila berhadapan dengan permasalahan mengenai jatidiri mereka, seperti KTP, SIM, dan lain-lain. Secara formal mereka akan tetap mengakui Islam sebagai agamanya, meskipun tidak menjalankan ajaran-ajaran Islam yang pokok, seperti shalat lima waktu, puasa Ramadan, zakat, dan haji (Koentjaraningrat, dalam Marzuki, 2006).

Masyarakat Jawa, terutama yang menganut Kejawen, mengenal banyak sekali orang atau benda yang dianggap keramat. Biasanya orang yang dianggap keramat adalah para tokoh yang banyak berjasa pada masyarakat atau para ulama yang menyebarkan ajaran-ajaran agama dan lain-lain. Sedang benda yang sering dikeramatkan adalah benda-benda pusaka peninggalan dan juga makam-makam dari para leluhur serta tokoh-tokoh yang mereka hormati. Di antara tokoh yang dikeramatkan adalah Sunan Kalijaga dan para wali sembilan yang lain sebagai tokoh penyebar agama Islam di Jawa. Tokohtokoh lain dari kalangan raja yang dikeramatkan adalah Sultan Agung, Panembahan Senopati, Pangeran Purbaya, dan masih banyak lagi tokoh lainnya. Masyarakat Jawa percaya bahwa tokoh-tokoh dan benda-benda keramat itu dapat memberi berkah. Itulah sebabnya, mereka melakukan berbagai aktivitas untuk mendapatkan berkah dari para tokoh dan benda-benda keramat tersebut.

\section{METODE}

\section{Instrumen Penelitian}

Instrumen penelitian yang digunakan dalam penelitian ini adalah angket adaptasi dari PMQ (Participant Motivation Questionnaire) yang dikembangkan Gill, 
Gross, dan Huddleston. Instrumen tersebut terdiri atas 30 item dengan 5-poin skala Likert dengan skala 1 (sangat tidak setuju) hingga 5 (sangat setuju). Instrumen penelitian terdiri atas 6 dimensi, skill development 7 item, status 7 item, energy release 6 item, team atmosphere sebanyak 4 item, affiliation 3 item, dan fitness 3 item.

\section{Teknik Pengumpulan Data}

Pengumpulan data dalam penelitian ini yaitu:

1. Mengumpulkan data mahasiswa yang bersuku Osing dan Suku Jawa.

2. Membagikan angket PMQ untuk diisi.

3. Menganalisis angket PMQ yang telah diisi oleh sampel.

\section{Teknik Analisis Data}

Teknik analisis data dengan uji manova digunakan sebagai alat analisis. Analisis multivariat digunakan karena pada kenyataannnya masalah yang terjadi tidak dapat diselesaikan dengan hanya menghubung dua variabel atau melihat pengaruh satu variabel terhadap variabel lainnya.

\section{HASIL DAN PEMBAHASAN}

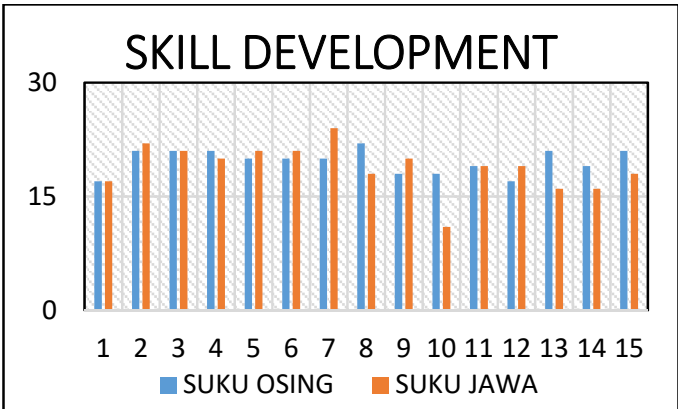

Gambar 1. Grafik Skill development suku Osing dan Jawa

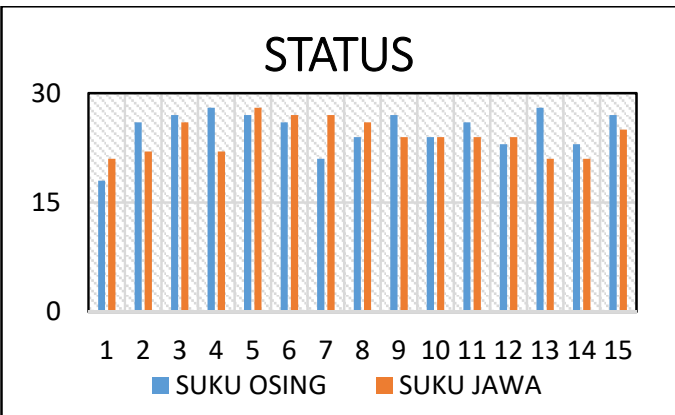

Gambar 2. Grafik Status suku Osing dan Jawa

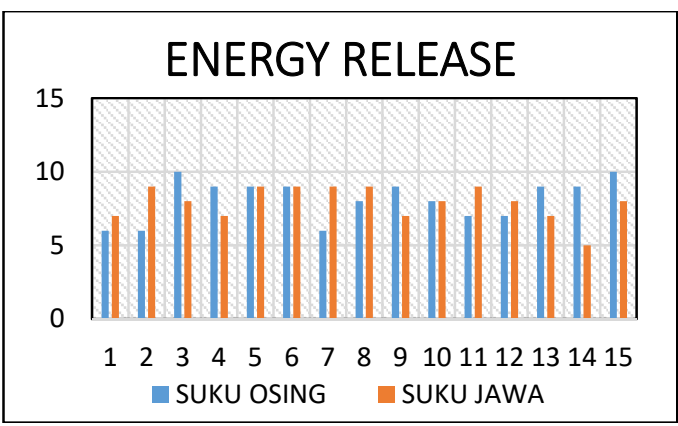

Gambar 3. Grafik Status suku Osing dan Jawa

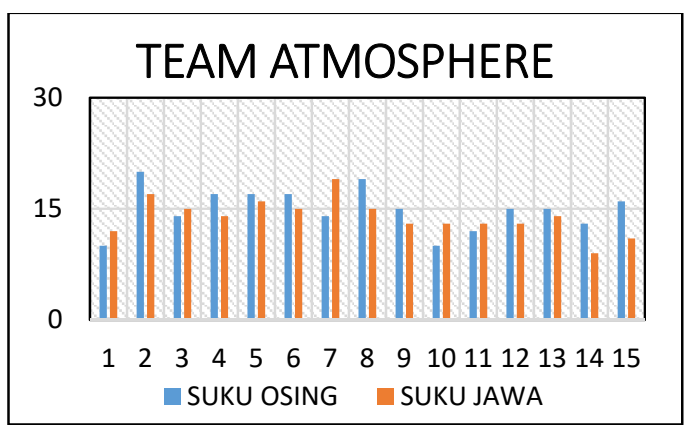

Gambar 4. Grafik Team Atmosphere suku Osing dan Jawa 


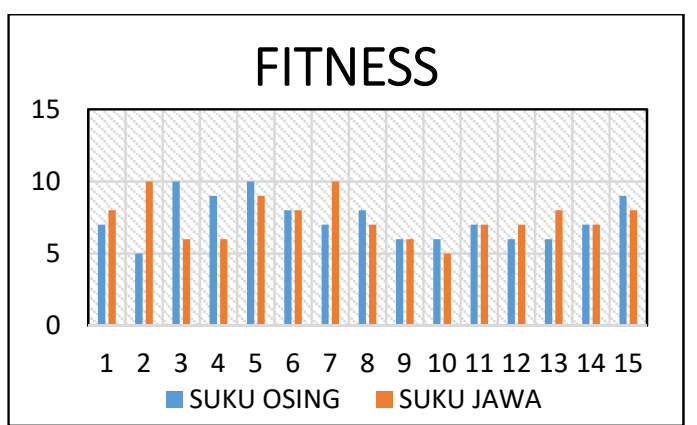

Gambar 5. Grafik Affiliation suku Osing dan Jawa

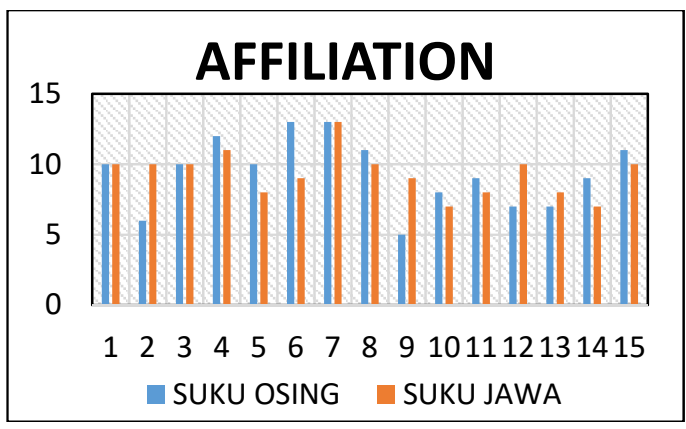

Gambar 6. Grafik Fitnes suku Osing dan Jawa

Pada grafik 1 sampai dengan 6 menunjukkan bahwa kondisi aspek skill development pada suku Osing memiliki ratarata yang jauh lebih tinggi daripada suku Jawa, dengan suku Osing memiliki nilai rata-rata sebesar 20,27 dan suku Jawa hanya 19,33 ; status pada suku Osing memiliki rata-rata lebih tinggi daripada suku Jawa, dengan suku Osing memiliki nilai rata-rata sebesar 25,13 dan suku Jawa 24,13; energy release pada suku Osing memiliki rata-rata lebih tinggi daripada suku Jawa, dengan suku Osing memiliki nilai rata-rata sebesar 8,13 dan suku Jawa 7,93; team atmosphere pada suku Osing memiliki rata-rata lebih tinggi daripada suku Jawa, dengan suku Osing memiliki nilai rata-rata sebesar 14,93 dan suku Jawa 13,93; affiliation pada suku Osing memiliki rata-rata lebih tinggi daripada suku Jawa, dengan suku Osing memiliki nilai rata-rata sebesar 9,40 dan suku Jawa 9,33; dan fitness pada suku Osing memiliki ratarata lebih rendah daripada suku Jawa, dengan suku Osing dengan nilai rata-rata 7,40 dan suku Jawa 7,47.

Dari keenam aspek tersebut merupakan indikator utama yang digunakan dalam menggambarkan potensi kedua suku sebagai referensi dalam menyeleksi atlet. Hal ini sesuai dengan penelitian Yan dan McCullagh (2004) yang meneliti tentang pengaruh budaya terhadap motivasi berpartisipasi remaja dalam aktivitas fisik. Bahwa anak-anak dan remaja yang berbeda sosial budayanya akan berbeda motivasi berpartisipasinya dalam aktivitas fisik dan olahraga. 


\section{SIMPULAN DAN SARAN}

Simpulan

Berdasarkan dari hasil penelitian

dapat diambil kesimpulan sebagai berikut:

1. Budaya suku berpengaruh dalam pengambilan keputusan tingkat motivasi berpartisipasi dalam olahraga.

2. Suku Osing lebih dominan daripada Suku Jawa pada aspek skill development, status, energy release, team atmosphere, dan affiliation. Sedangkan pada aspek fitness Suku Jawa lebih dominan daripada Suku Osing. Sehingga Suku Osing lebih progresif dalam peningkatan prestasi olahraga.

\section{Saran}

Berdasarkan kesimpulan yang diperoleh dari hasil penelitian yang dilakukan, peneliti memberikan saran sebagai berikut:

1. Bagi pelatih olahraga disarankan untuk dapat memahami atlet yang berbeda suku dalam membuat model latihan dan meningkatkan prestasi, karena setiap atlet yang berbeda suku memiliki motivasi yang berbeda.

2. Bagi peneliti hasil penelitian ini dapat digunakan dalam penyusunan data psikologis atlet, sehingga menjadi dasar dalam pemilihan atlet dan pembuatan program latihan.

\section{DAFTAR PUSTAKA}

Abbas, S.A., Norouzi, R.S.H., Kalateh, M.S., \& Fathi, H. (2012). Analysis of Motivation for Participation in Sport for All. International Research Journal of Applied and Basic Sciences, vol. 3(4), 790795,2012.

Anastasia, M. dkk. (2013). Kebijakan Akselerasi Pengembangan Kawasan Wisata Osing Berbasis Democratic Government. Penelitian Unggulan Universitas Jember

Barber, H., Sukhi, H., \& White, S.A. (1999). The Influence of ParentCoachs on Participant Motivation and Competitive Anxiety in Youth Sport Participants. Journal of Sport Behavior, v22 12 p162(1).

Brown, J., Siraje, S.A., \& Reuben. (2011). Decision making Styles East and West: Is It time to move beyond cross-cultural research. International Journal of Sociology and Anthropology, Vol. 3(12), pp. 452-459.

Darmawan, D. (2008). Teori Motivasi. Surabaya: Metromedia Education. 
Fan, Y. (2000). A Classification of Chinese Culture. Cross Culture Management, 2000. 7:2, 3-10.

Fathoni, H.A. (2006). Antropologi Sosial Budaya. Jakarta: Rineka Cipta.

Herusatoto, B. (2005). Simbiolisme Dalam Budaya Jawa. Yogyakarta: PT. Hanindita Graha Widya.

Koivula, N. (1999). Sport Participation: Differences in Motivation and Actual Participation due to gender typing. Journal of Sport Behavior, 1999. 22, i3 p360(2).

Maksum, A. (2009). Handouts Sosiologi Olahraga. Surabaya: Universitas Negeri Surabaya.

(2011). Psikologi Olahraga Teori dan Aplikasi. Surabaya: Unesa University Press.

. (2012). Metodologi Penelitian dalam Olahraga. Surabaya: Unesa University Press.

Marzuki. (2006). Tradisi dan Budaya Masyarakat Jawa dalam Perspektif Islam. Yogyakarta: Universitas Negeri Yogyakarta.

McClelland, D. (2009). David Mclelland's Motivational Needs Theory.

Park, S.R. (2006). A Cross-Culture Study of the Motivational Factors Affecting Individuals' Decisions about Participating in Action Sports between Korean College Students and Their American Counterparts.

Sheikh, M., Afshari, J., \& Sheikh, H. (2011). Comparing Sport Orientation between Individual and Team Sport, and It is Relation to Sport Participation Motivation. American Journal of Scientific Research, 30(2011), pp. 28-35.

Sit, C.H.P. \& Lindner, K.J. (2000). Perceived Physical Ability and Sport Participation Motivation of Hong Kong Children with Disabilities. The Hong Kong Journal of Sport Medicine and Sports.

Vallerand, R.J. (2004). Intrinsic and Extrinsic Motivation in Sport. Encyclopedia of Applied Psychology, Vol 2.

Yan, J.H., \& McCullagh, P. (2004). Cultural Influence on Youth's Motivation of Participation in Physical Activity. Sport Research Intelligence Sportive.

Zahariadis, P.N., \& Biddle, S. J. H. (2000). Goal Orientations and Participation Motives in Physical Education and Sport: Their Relationship in English Schoolchildren. The online Journal of Sport Psychology, Vol2. 